\title{
PULSÕES NA ARTE MBYÁ-GUARANI: OS SEUS PENSAMENTOS E SENTIMENTOS REFLETIDOS ATRAVÉS DOS OBJETOS CERÂMICOS
}

FRANKLIN DA SILVA ALONSO ${ }^{1}$

UERJ

RESUMO: Esse ensaio se refere à investigação acadêmica iniciada por mim no curso de Mestrado em Arte, Cultura e Cognição na Universidade do Estado do Rio de Janeiro entre 2012 e 2014, tendo por objeto de estudos a cerâmica dos índios Mbyá-Guarani em suas aldeias localizadas nas cidades de Niterói e de Maricá, Rio de Janeiro. Percebendo haver atualmente um distanciamento desses indios com a arte oleira, buscou-se revitalizar nesses ambientes tal prática por meio de oficinas de trabalho coletivo junto às crianças mbyá, apresentando-lhes as características morfológicas e pictóricas tradicionais que os itens cerâmicos simbolicamente expõe para haver a devida valorização de sua etnicidade frente à sociedade contemporânea dos não índios.

PALAVRAS-CHAVE: mbyá-guarani; cerâmica; arte; educação; identidade.

ABSTRACT: This paper covers the academic research carried out during my Master's degree studies (Master in Arts, Culture and Cognition, University of the State of Rio de Janeiro, between 2012 and 2014) about the ceramics of the Mbyá-Guarani people, in two villages located in cities of Niterói and Maricá, Rio de Janeiro. Realizing that these people are now distant from the ceramic art, we sought to revitalize such practice in these environments through collective workshops with the Mbya children, presenting them with the traditional morphological and pictorial characteristics that ceramics items symbolically expose, in order to develop proper appreciation of their ethnicity before the non indigenous contemporary society.

KEYWORDS: mbyá-guarani; ceramics; art; education; identity.

\section{Constatando que ao nos confrontarmos com certas coletividades que por muitos homens "modernos" ainda são apercebidas como}

\footnotetext{
${ }^{1}$ Graduado em Educação Artística com Habilitação em História da Arte pela Universidade do Estado do Rio de Janeiro (2005) e Mestre em Artes Visuais na linha de estudos em Arte, Cognição e Cultura pela mesma Universidade (2014). Atualmente é professor de Educação Artística nas Redes de Ensino do Estado do Rio de Janeiro e da Cidade de Mesquita (RJ). E-mail: carvalonso@uol.com.br.
} 
"culturas primitivas", quantas não foram as vezes que ignoramos a complexidade existente em suas formas próprias de lidar com a vida? Comumente não minimizamos sua importância, seu caráter de propriedade substancial que em cada ato e comportamento daqueles grupos demonstram dentro de uma história definida seu entendimento de existência?

Se bem ponderado, será que não concluiremos, ainda, que, de um modo muito análogo aos procedimentos tomados por essas alteridades, não é também comum que os autodenominados "civilizados" desenvolvam seu arco histórico-social por meio de um cabedal de posturas comunais de organização na ordem do sacral, do político, jurídico e do campo econômico que confirmem uma eficiência presentificada frente ao mundo por modus operandi endógenos? E essas determinadas mostras atitudinais de uma população não seriam aí plenamente ratificadas pela cultura material que as representam, onde se elaboram objetos que tradicionalmente agem em favor de seus criadores/fruidores, garantindo-lhes certo bem-estar? Via de regra, esses artefatos habituais ao grupo não são igualmente contenedores de potências acreditadas pelos sujeitos (que deles se instrumentalizam) como recebedoras de uma "aura" de honra e valor ligada a essas suas certezas?

Desta feita, tendo tais concepções basais em mente, tentei durante meus primeiros contatos com os Mbyá-Guarani (realizados durante o desenvolvimento de minha pesquisa de Mestrado pelo Instituto de Artes da Universidade do Estado do Rio de Janeiro, entre os anos de 2012 e 2014) compreender um tanto a respeito dos hábitos socioculturais e realizações materiais decorrentes desse coletivo por muitos ainda percebidos, de maneira bastante estereotipada, como "selvagem".

Mas como apropriadamente fazê-lo? A resposta se deu mais especificamente através da expressão artística cerâmica promovida por um programa educacional que uniu a metodologia da pesquisa-ação ao método pedagógico idealizado por Célestin Freinet na(s) aldeia(s) mbyáguarani - Tekoa Mboy y-ty (Niterói) e Tekoa Kaaguy Hovy Porã (Maricá). Daí ter trabalhado nesse estudo com uma perspectiva que abrangeu não só a Arte e a Educação, mas também a Etnografia, a História e a 
Arqueologia.

E, mesmo que aparentemente hoje as obras feitas de barro não tenham tanto vigor compositivo como já tiveram anteriormente dentro dos espaços de algumas de suas aldeias, parecem ser as subjetivas ideias da própria genealogia guarani que educacionalmente resguardam a possibilidade na continuidade de seus costumes (seu modo de viver, aquilo que chamam por nhanderekó ou teko). Sempre auxiliando o grupo, contações mitológicas e apresentações plásticas conceitual e pragmaticamente se agregam para compor e garantir uma vivência boa e harmoniosa com as mais "díspares" instâncias existenciais - homens, animais, vegetais, minerais, sendo avalizados e amparados por suas deidades. Desde o fabrico e uso no passado congressional dos objetos argilosos - dos Proto-Guarani, ou seja, da ascendência dos atuais Guarani que, segundo André Prous (2007), já peregrinavam há muitas eras atrás pelas terras meridionais americanas - até a sua atualidade em esporádicas ocorrências, principalmente pelo exercício das atividades oficineiras que recentemente incidiram na(s) aldeia(s) por meio dessa proposta de pesquisa, traços expostos na morfologia dessas obras de barro parecem ter sido mantidos e protegidos pelos pujantes significados que subjazem a sua materialidade - apesar, claro, das frequentes cooptações que sofrem da sociedade dita "cosmopolita".

No transcurso desse projeto multidisciplinar - e com o entendimento sobre a relação existente entre a arte cerâmica e as demais manifestações socioculturais mbyá-guarani - se atentou então para a prerrogativa de que, em decorrência do dinamismo pelo qual passa a sua sociedade (engendrado ou não pelas inevitáveis frequentações estabelecidas conosco, isto é, com os seus "outros"), partes construtivas da sua tradição oleira possivelmente podem não ter "desaparecido" por completo.

Ora, se a vida é movida por ocorrências despendidas por valores que também podem variar, por que não aventar que certos prismas importantes para a costumeira significação da cerâmica mbyá talvez estivessem sendo, no decorrer do tempo simbolicamente transpostos por esses indivíduos, para outros tipos de apresentação, sob outras situações e momentos que não os costumeiros de seu antanho cultural? Por que não imaginar que seu simbolismo pudesse se exprimir por 
outros meios? Por exemplo, símbolos gráficos da etnicidade mbyáguarani agora surgem em peças até recentemente "atípicas" a sua tradição material, como colares, saias e pulseiras feitas em miçangas de plástico coloridas (o que não desabona o seu fazer tradicional com sementes), mas que na atualidade - entre outros objetos mais sustentam a economia criativa da aldeia.

Não obstante, se assim o é, se questiona se não seria este um indício de que há uma promoção mbyá marcante na percepção de novas possibilidades construtivas - independente da motivação que as conduz -, baseadas em e por ideias vanguardistas, desembocando no uso de outros aparatos para a sua expressividade. Convivendo com os MbyáGuarani (especificamente com os Mbyá assentados em Niterói/Maricá, Rio de Janeiro) depreendi que os emblemas visuais de sua filosofia espiritual (e que eram antes manifestados na materialidade do barro) hoje tendem a ter maior incidência no método de confecção e decoração de sua cestaria, na arte em madeira, nos colares, pulseiras e brincos, saias, esteiras e em outras formas de seus procedimentos artísticos. Tudo isso, contudo, não quer dizer que outrora esses símbolos étnicos fossem exibidos exclusivamente pela arte cerâmica, mas que com a sua notória escassez, alguns traços culturais inevitavelmente se perderam (SHADEN, 1974), nuances que desde sua ancestral ascendência gráfica tupi-guarani advogavam na complexidade da extensão cosmogônica de seu pensamento e que não mais se mostram tão facilmente visíveis na contemporaneidade. Agora, esse íntimo vigor remanescente torna-se mais evidente por outros corpos.

Mesmo quando objetos e técnicas não correspondem àqueles corriqueiramente regulares de sua cultura, esses signos poeticamente continuam se presentificando no seu coletivo. Isso nos propõe que os novos artigos pelos quais hoje se expõem a sua etnicidade estejam, aos poucos, se incorporando à sua feição artística contemporânea mostrando, entretanto, certo resíduo que não pode ser traduzido significativamente em outro meio que não o oleiro. Isso é acatado a partir da crença de que as mudanças metodológicas e morfológicas adotadas no fazer do artefato não são suficientes para esvanecer o poder das mitologias e dos devidos fundamentos culturais confiados pelos Mbyá-Guarani. Tanto que, como argumentado, apesar de soar 
como submersa a sua lembrança quanto à artesania cerâmica, os demais itens por eles criados através de outras mídias atestam ter em comum certas visualidades que sustêm subjetivamente o seu fervoroso ethos. Considerando que, como acervo incorpóreo de seu patrimônio, para este ethos não importa o meio usado (conquanto que garanta uma inteligibilidade comunicativa para a comunidade mbyá, pois a arte, repito, fazendo parte dessa identidade, primordialmente responde a respeito de pessoas e não a respeito de suportes materiais), o dado que aí é relevante é que ele ampara os mecanismos das mais diversas ciências culturais a serem sempre pelos Mbyá-Guarani apreendidas e transmitidas entre $\mathrm{si}^{2}$.

O artefato ganha aí a propriedade de ser uma forma de garantia na constituição afirmativa contemporânea do que é ser essencialmente um Guarani, apesar dos contínuos contatos com outras comunidades. Afinal, na realidade de fricção interétnica vivida entre o grupo índio e a sociedade não índia envolvente, observamos que “...todo grupo humano está em constante mudança... As pessoas possuem múltiplas auto representações, elas se comportam de diferentes maneiras em diversos contextos, em constante mutação..." (PELEGRINI e FUNARI, 2008, p. 24).

Assim, diante do mundo em que vivemos, é aportando sua atenção ao prisma indígena de autopreservação físico/simbólica que Isabela Nascimento Frade e Marluce Reis (2010) salientam que os Mbyá têm seguido dois tipos de posicionamento ante o processo de tentativa de erosão cultural contra si. Um desses modos é expositivo em clara resistência feita, marcado por procurar frente à interferência do seu "outro" "reduzir a cultura, buscar suas formas essenciais, tornando-as contrastantes nesse diálogo cultural opressivo" (FRADE e REIS, 2010, p. 43). Já a segunda disposição, ao contrário, aposta que para resguardar todas as suas verdadeiras virtudes dos "citadinos", deve reservar as

\footnotetext{
2 "O sistema cosmológico de uma sociedade indígena é uma combinação de vários tipos de conhecimento, entre os quais poderíamos distinguir o conhecimento empírico e o conhecimento metafórico. O primeiro é derivado da observação e experimentação, baseado essencialmente na percepção dos sentidos, como por exemplo, a constatação da anatomia, dos hábitos alimentares e reprodutivos dos animais. O segundo advém da conjunção do conhecimento empírico com crenças e experiências que não se restringem a percepção imediata e física das coisas, mas se reportam a uma outra dimensão que poderíamos chamar de 'metafísica', como o lugar de seres imateriais como espíritos, almas, etc., na ordem das coisas. Ambos esses tipos de conhecimento são construídos culturalmente, e é errôneo supor que qualquer tipo de conhecimento, mesmo o dito científico, esteja dado na natureza" (RAMOS, 1988, p. $39)$.
} 
mostras de sua cultura exclusivamente para o uso do grupo e, dessa forma, aos nossos olhos ocidentalizados "inversamente, tornando-as invisíveis" (FRADE e REIS, 2010, p. 43). Destarte, aos juruá3, os MbyáGuarani expõem dados visuais que nos pareçam familiares, "assumindo as formas dominantes" que tanto preponderam em nosso meio (FRADE e REIS, 2010 , p. 43).

No primeiro caso, verifica-se que o artista guarani escolhe imprimir em suas representações um sinal étnico, selecionando qual propriedade estética reproduzida dentre suas gerações lhe dará maior amparo por seu suposto "exotismo", ganhando a visibilidade desejada diante da sociedade metropolitana. Uma "bandeira" que pode se rever em reconhecimento das e nas suas demandas de direito às terras, de respeito a sua identidade e igualdade social, de aceitação de sua cultura por parte dos "brancos". Na outra situação, o Mbyá depreende - e o demonstra por meio de suas obras - que apesar das aparências materiais transformadas pela aproximação intercultural, jamais deixará de ser quem é. Inteligente, ao invés de afastar-se completamente do não índio, "fagocita" da cultura material cosmopolita certos elementos, tomando por "empréstimo" alguns de seus dados plásticos. O artista mbyá-guarani, não raro, sonda ter aí acesso a esses subsídios, solicitando para si a mesma valência de usufruir das "benesses" que acaso perceba neles existirem - formais e ideacionais -, inclusive, sendo esta até uma "porta" facilitadora à entrada de seus artefatos no comércio da nossa sociedade. E esse dado recorrente da precisão em se integrar na economia do não índio é relevante (e até não pode ser desprezado) porque hoje boa parte dos recursos financeiros angariados nas suas aldeias é advindo do trabalho de artesanato. Nessa perspectiva, a arte guarani expõe aspectos derivados da apropriação de especializações técnicas voltadas ao fazer estético, municiando-se de aparatos que dialoguem com outros públicos culturais aos quais, principalmente pelo fator econômico, então se destine.

\footnotetext{
3 “Os Guarani-mbya referem-se aos brancos como juruá. Não se sabe ao certo desde quando empregam esse termo, porém, hoje ele tem uso corrente e parece destituído de seu sentido original. Juruá quer dizer, literalmente, 'boca com cabelo', uma referência a barba e ao bigode dos europeus portugueses e espanhóis conquistadores. De todo modo, o nome juruá foi criado a partir do contato com os brancos colonizadores e passou, com o tempo, a ser uma referência utilizada genericamente a todos os não-índios" (LADEIRA, 2008, p. 73).
} 
Além dessa adequação, por um lado, a arte nativa (por muitos apontada como "exótica", "selvagem", "ingênua") ainda se arregimenta por uma ideia errônea do juruá de que sua elaboração se localiza em uma escala inferior no "mostruário" da criatividade humana. Ela seria um material onde "o artesanato nasce do fazer, e... a arte, do pensar" (FRADE, 2006, p. 42). Mas... para se fazer qualquer coisa que seja, não se tem que pensar? Ou a obra é resultante de uma inspiração divina, recoberta por uma aura de realização ultra-humana, ofertada ao artista em um momento especial de sua vida? Ou seria ainda ela espontânea e vinda do resultado acéfalo onde o gesto autômato simplesmente "se ocupa", sem sentido e sem direção? Se respondermos positivamente a essas questões, decerto se justificaria a dicotomia entre arte e artesanato... 4

Em suma, é muito forte a apreciação daquele outro prisma possível nessas assimilações de métodos e insumos construtivos considerados (por nós, não índios) até então como "não convencionais" de apresentação nos artefatos mbyá-guarani: o caráter comercial. Haja vista que, quando o criador índio assume para si a responsabilidade em manejar dados diferentes dos seus costumeiros para obter maior proximidade ao aspecto formal dos objetos ou gostos juruá, possivelmente ele esteja buscando uma familiaridade visual melhor ajustada à desse "civilizado" para se favorecer no processo de venda de seus artefatos. Nada impede aí que eles se tornem signos representativos de identidade - mesmo que estes se configurem de modo estereotipado por quem os vê. Cientes disso, finalmente podemos aventar que:

Os contextos de uso e circulação das peças mudam de formas significativas quando objetos e artefatos entrem no circuito comercial interétnico: tornam-se emblemas de identidade étnica, peças de museus ou "obras de arte". Neste caso seu modo de agir sobre o mundo muda radicalmente e surge a questão da aplicabilidade de nossos valores com relação à importância da

\footnotetext{
${ }^{4}$ Ora, convenhamos que "O pensamento em arte também nasce dessa operosidade, um fazer que se estetiza, que age e pensa na forma. E é por isso que a dicotomia arte e artesanato também é falsa: ela está a serviço da desvalorização do corpo, nega uma inteligência artística primordial, corporificada, organicizada e organicizante. Mesmo que puramente conceitual, um fato artístico acontece no mundo das coisas; as coisas virtuais são também constituídas a partir das relações concretas" (FRADE, 2006, p. 45).
} 
criatividade e da individualidade na produção artística, enquanto uma grande variedade de concepções nativas existe a este respeito (LAGROU, 2009, p. 66).

Entretanto, daí pode surgir a seguinte dúvida:

Será que o impacto estético e a capacidade de inovação sempre andam de mãos dadas, ou pode o nosso fascínio por artes que se desenvolveram fora da tradição erudita se explicar exatamente pela coerência do estilo como consequência da resistência à inovação excessivamente modificadora? (LAGROU, 2009, p. 66).

Nos coloquemos na condição de pessoas que percebam que, apesar da possibilidade dos itens materiais indígenas engendrarem no mundo "urbano" por intermédio do comércio, em linhas gerais, dele ganhando propriedades que não Ihes sejam "naturais" (mas advindas da concepção de nossas sociedades), nada afiança que a ocorrência de sua reprodução seja considerada como capaz de fazer com que percam essa mesma sua "espontaneidade". O Mbyá-Guarani continua a atribuir aos seus objetos uma importância peculiar pela sua "essência" mantenedora, pois, como ainda alerta Els Lagrou, "no universo artefatual ameríndio... a cópia é muitas vezes considerada como sendo da mesma natureza que o modelo, e tende a ser produzida através das mesmas técnicas que do original" (LAGROU, 2009, p. 39). De um modo ou outro, o Mbyá permanece demonstrando o que sente em seu íntimo por meio das peças respeitosas aos seus padrões e às determinantes mitológicas de sua tradição. A sua pulsão em comunicar-se e aprazer às solicitações estéticas juruá envoltas na relação de comércio o conduz a responder aos ditames plásticos da cultura hegemônica sem, contudo, degradar a qualidade simbólica de seus feitos e mesmo no processo de exposição e venda desses itens culturais, o cuidado mbyá-guarani em expor os seus apontamentos de cosmovisão é, contudo, ainda demasiado marcante.

$O$ relato de Cristina Campos, pesquisando os objetos de arte mbyá na aldeia de Niterói, nos confirma que:

Os cestos, junto a outros objetos artísticos, encontramse dispostos em uma ampla bancada para serem comercializados aos turistas que visitam a aldeia. Os objetos são dispostos por aproximações de categoria e autoria, que por sua vez são agrupados de acordo com 
os núcleos familiares. Conferem um modo de exposição segundo critérios estéticos autóctones. Essa disposição e agrupamento se aproximam do modo como os Guarani concebem a organização social e cosmológica do grupo no espaço/tempo (Ara Ypy), uma organização que prima por seus núcleos familiares, sejam eles da ordem da natureza ou da sobrenatureza (CAMPOS, 2012, p. 80).

Se sancionada a iniciativa de trabalho artístico devotada à sua venda, pela ilustração citada de considerações endógenas para a sua demonstração, não fica claro que o pensar indígena é sobremaneira astucioso? Ele não anteviu e realizou conforme aquilo que melhor se adequasse à meta que estabeleceu (a venda), mas preservando determinadas premissas culturais para expô-las? Onde se encaixa aí o "encalacrado" conceito citadino de artesanato diferenciado tanto assim da idealização que o senso comum tem de arte?

O que realmente devemos nos deter nesse sistema construtivo mbyá é, independentemente da variação estética, a conservação dos elos simbólicos e da posse comunicativa existente entre ele e a sua sociedade, sempre norteado por sua noção de espiritualidade. O imprescindível não é manter o objeto morfologicamente imutável, mas garantir o poder de permanência do que está "por trás" dele: o caráter de produto surgido de dogmas baseados no ethos de sua vida comunal.

Retornando, porém, efetivamente às questões da atual feitura cerâmica nas tekoa (aldeias) mbyá de Niterói e de Maricá, mesmo que inicialmente eu cogitasse que não pudesse me associar à profusão de suas certezas pela "distância" de aproximação imanente às proposições socioculturais daqueles homens (mais notadamente as de cunho cosmológico), estava ciente de que se oportunizava pela via do pensamento e da articulação artístico-pedagógica, a chance de notar a retomada mbyá no manuseio poético com a argila e, daí, todo o possível eco que dele reverberasse em sua estrutura societal.

Mas como fazê-lo? Ora, por intermédio de oficinas de trabalho cerâmico que, diante da etnicidade reconhecida desses índios, pudesse harmonizar durante a sua lide a incorporação de aspectos tidos por eles como tradicionais na sua história da feitura argilosa com outros informes advindos dos dados tidos de nosso contexto contemporâneo 
globalizado. Ora, será que o resultado desses encontros já não pareceria ser uma mostra da dinâmica sociocultural pela qual essa agremiação humana passou (e há de passar) em seu arco espaço/temporal?

Contudo, lembremos que já que a artesania mbyá realizada nas aldeias de Niterói e de Maricá se destinam quase exclusivamente à venda desses artigos, seus moradores alegavam não ter tempo suficiente para abdicar da sua dedicação a essa prática focada ao comércio e participarem das oficinas cerâmicas propostas por meu projeto. Além disso, existiam - e existem - também fortes determinantes míticas que restringem os adultos no manuseio constante com o barro, pois acreditam que fazê-lo desmedidamente (desrespeitando a mãe terra) pode acarretar diversos malefícios aos Mbyá. Minha "clientela de trabalho" se afunilou então para o atendimento daqueles para com que os gravames de ordem mítica no trato direto com o solo não são tão incisivos: as crianças.

Minha intenção aí, sendo de caráter artístico, era a de levar até elas certo saber histórico, técnico e étnico sobre a sua materialidade ancestral argilosa por meio de uma metodologia específica de atividades, nutrindo perspectivas cognitivas (emocionais e intelectivas) a partir de ações oficineiras. Um espaço que, no futuro, banhado pelo poder de consciência e de autonomia, poderia vir a estimular esses meninos a atuarem politicamente a favor de sua etnicidade, disseminando pela arte cerâmica os dados identitários de sua cultura. Muito mais do que uma atuação instrucional, visei, desta feita, estabelecer nesse processo de ensino/aprendizado da arte cerâmica uma ambiência das oficinas como locus democrático, solidário, com intuição criativa e propenso à expressão individual/coletiva dessas crianças.

Faço aqui, portanto, um relato bastante breve das atividades realizadas nas aldeias, quando as convidei para delas participar, utilizando o barro ainda em estado de pedra para que juntos pudéssemos esfarinhá-lo em pó e agregar a ele água, tendo um material mais maleável para trabalharmos.

Sentados no chão de terra, solicitei a elas que desmanchassem todas aquelas pedras para darmos começo às nossas oficinas cerâmicas. E sendo o princípio de tais tarefas oficineiras achei ser necessário ter 
com os participantes uma conversa e explicação da proposta do dia, pretendendo que eles soubessem o contexto do por que estavam desenvolvendo determinada ação. Isso Ihes daria, penso eu, um maior amparo à evocação consciente de sua imaginação e de sua sensibilidade durante o processo construtivo.

Enquanto trituravam os blocos de argila seca (impactando-os contra o solo), fui explicando aos poucos que aquela porção de terra era formada por outras "pequenas pedrinhas" que juntas constituíam a argila (nhaiu). E agregando água a esse pó resultante, conseguimos um material mais mole, mais plástico, mais dúctil para os fins de nossa atividade artística/educacional.

As conclusões as quais alcancei até aquele momento de experimentação nos trabalhos realizados com as crianças era a de que, para que os participantes pudessem dirigir bem a sua artesania com a argila, seria imperativo primeiro obedecer à natureza daquele mesmo insumo, precisando melhor conhecê-lo, pois a característica física do barro sempre nos convida a tocá-lo, sendo um material predominantemente agregador no manuseio direto com ele próprio e, subjetivamente, também com todos aqueles com os quais dividimos essa experiência. Nesse ponto da ação oficineira, o intento era o de estimular a sensibilização dos pequenos Mbyá na observação da mudança de estado físico do material argiloso, dando-lhes a chance de analisar a sua variação, quando avaliamos em nossa conversa informal tal fato. Como percebido e dito por um dos meninos: "a terra fica mole quando é molhada, que nem em dia de chuva".

O segundo passo metodológico de trabalho foi lhes dizer que os antigos Guarani construíam seus potes, suas panelas, seus pratos, suas cumbucas, etc. a partir de "cobrinhas" de barro. Usei com eles expressões que detinham elementos animais durante o procedimento de construção, já que, sendo na sua maioria crianças pequenas e acostumadas em conviver com esses tipos de seres mais que eu, possivelmente pela linguagem utilizada Ihes criaria uma maior empatia comigo e captação daquilo tudo que Ihes estava sendo proposto.

Eu focava naquela oportunidade que se capacitassem a decodificar a potencial linguagem de sua sensibilidade audiovisual ao se aproximarem mais de $\mathrm{mim}$, refinando o seu sentir, refinando a 
aspiração de seus desejos e apurando, enfim, a sua inspiração criativa ao se utilizarem da matéria-prima argilosa. Desta feita, em pouco tempo e sob minha orientação, cada um desses meninos Mbyá teria um punhado de "cobrinhas" de barro em suas mãos para começar a sua lide artística.

Sugeri começarmos a fazer um pote tradicional cerâmico (karo), mostrando-Ihes como elaborá-lo através da minha ação prática. Cada qual, com suas "cobrinhas", passou a imitar meus gestos, construindo a base da sua devida cumbuca. Deste modo, pedi para pegarem um desses roletes de argila e enrolá-lo como se fosse um "caracol". E o tendo como fundo da peça, pedi que assentassem outra "cobrinha" nas bordas para levantarem as paredes do karo.

Com essas explicações básicas edificamos juntos alguns potes com certa facilidade, tendo a participação de todos, dos pequeninos Mbyá aos maiores. Um evento que assim se delineou como território de convivência criativa, pois nesse coletivo se favorecia o possível acontecimento de domínios e interação nos diálogos feitos com nossos "outros" (conversações instituídas entre eles e comigo também). O trabalho estava sendo assim promovido em um ambiente de segurança e amizade, mexendo com o barro e ativando plasticamente as experiências trocadas entre todos. Tanto o é que, durante o método de construção dos karo, os jovens maiores começaram a fazer por conta própria figuras com o nhaiu: bonecos, um caminhão, moto e panelas e os pequenos os acompanharam. Deu-se aí a essa garotada a primeira oportunidade de usar sua imaginação moldando obras com a argila, mas sem qualquer tipo de restrição criativa, o que favoreceu (a meu ver) a possibilidade de comporem imagens de grande teor e peso simbólico para si, "trazendo à luz" aspectos reconhecíveis de suas vidas cotidianas.

Decorre que, mesmo que durante esse aprendizado pessoal surgissem juízos mostrados por elementos argilosos divergentes daqueles habituais do grupo - e que comigo estavam então aprendendo -, notemos que as necessidades criativas de cada um dos participantes tinham de ser (por mim e pelos outros integrantes das atividades) eticamente observadas, reconhecidas e respeitadas, fato este que nos conduziu a um diálogo permanentemente contínuo. Foi este o instante 
da atividade em que se esperou tomar corpo as possíveis trocas de experiências realizadas entre os educandos, justificando suas motivações e empenhos que contribuíram para a confecção de determinada cariz morfológica em suas peças. Pela ação oficineira na Tekoa Mboy y-ty (Niterói) e Kaaguy Hovy Porã (Maricá) foi então plausível pensar que se cunhava ali um ambiente de entendimento onde se possibilitava dar voz aos envolvidos para uma real conversação. E a comunicação visual e a práxis com a matéria-prima do barro foram aí os estatutos que fizeram com que esses pequeninos interagissem, se integrassem, se (re)conhecessem como autores mbyá.

É com base nessa pontuação que também pondero sobre outro aspecto: que essa dinamicidade em seus conhecimentos esteja vinculada não só aos seus dogmas de tratamento, mas globalmente coligada ao espaço circundante (social e natural) com o qual os MbyáGuarani convivem e onde a manifestação artística é parte vital do seu dia a dia, sofrendo dele as devidas mudanças quando preciso. É nas relações entre os itens culturais e seus construtores/fruidores onde se postam os significados detidos tanto na praticidade rotineira quanto apreciativa e ritual de um coletivo determinado; é onde a estima atribuída às peças pode acontecer pelo seu efetivo emprego.

Isso considerado até porque, nas tarefas oficineiras, um dos dados substanciais a dali se extrair parece ter sido o efeito da descrição mitológica que as crianças ouvem constantemente dos "mais velhos" na tekoa, o como (na sua expressão sobre o objeto de barro tanto quanto sobre outros materiais) o mito nelas organiza certas imagens internas e às quais os pequenos também já atribuem certos sentidos endógenos. Assim, educacionalmente, a arte cria a possibilidade da formação de imagens substanciais que fluem pelo território subjetivo na sociedade mbyá, tomando corpo vivo através de seus artefatos. Confirmando essa assertiva, Frade até se propõe a analisar o aspecto da desmaterialização dos objetos tornados vivos e emblemáticos em uma sociedade, onde estamos "imersos em um ambiente onde o signo tem mais valor que o real, onde a relação com a realidade se desfaz em estímulos cambiantes" (FRADE, 2006, p. 21).

E considerando a atual realidade mbyá de contato conosco (os juruá), se torna crucial também notar como os pequenos Guarani 
lidaram desta feita com tudo aquilo que, massivamente, receberam/recebem de informações da sociedade não índia. Esses jovens colocaram-se em meio ao dilema de compreender as estruturas narrativas e os simbolismos do que Ihes foram perpassados pelas duas culturas, a de seus ancestrais e aquela sua "outra" com a qual tinham/tem acesso e envolvimento diários: a cultura "branca". Uma boa ilustração disso foi, após a construção e pintura de emblemas étnicos de sua cultura (de origem mitológica) nas peças que fizeram, se dar ainda a implementação plástica do elemento "asa" em algumas das panelas e copos realizados pelas crianças nas oficinas.

Ora, se bem ajuizarmos que a atenção e a fruição sobre um objeto são fomentos basais à consciência humana sobre a arte, não podemos igualmente pensar se a práxis cerâmica promovida nos encontros oficineiros exercitados com certo valor de uso, induziria as crianças mbyá a conscientemente ponderar sobre o que ali estivessem aprendendo e, desta feita, também fazendo? Dito isto porque os dados da sua laboração formal (como os tipos de constituição plástica, adereços, impressões superficiais e suas pinturas) não pareciam assim estar só restritos a uma vista de reprodução de suas ancestrais peças culturais, mas dentro de um âmbito mais amplo de utilização no seu cotidiano, expuseram as transformações morfológicas acontecidas durante esse sistema de aprendizagem (no caso, as "asas" nos potes) caracterizando-se como espelhos de seus novos anseios, pulsões de pensamentos e de sentimentos constituidores de parte ressignificada de sua identidade contemporânea.

\section{Conclusão}

No que tange à convivência e à lide oficineira nas aldeias guarani, o que aqui tomo por conclusão parcial é que o empreendimento da pesquisa trouxe, sim, àquelas crianças mbyá-guarani o conhecimento material e prático das suas obras ancestrais de barro, mas aí acrescido dos saberes que já detinham cotidianamente no ambiente vivido nas tekoa. Informes, não esqueçamos, que se valem também daquelas agregações tangíveis e intangíveis que essas crianças 
absorviam/absorvem a todo momento da cultura juruá, aparentando ter sido a convergência destas diversificadas fontes que lhes favoreceram no desejo pulsional em constituir para si mostras físicas significantes do que é ser hoje, em sua concepção, um Guarani.

E como aludido nesse ensaio, não é por existir uma educação tradicional (mítica) que tal processo despenderia os Mbyá em seus justos ensejos em conhecer, aceitar e em conduzir-se rumo à iniciativa de algum ineditismo em suas obras realizadas. Como resultados de práticas artísticas, seus objetos permitem variações nas suas formas, texturas e cores, basta percebermos terem uma poderosa estrutura simbólica "por trás" de si chancelando as propriedades palpáveis de reconhecimento étnico mbyá-guarani. Desta feita, por intermédio da sua arte com o barro, está disposta toda uma filosofia, convertida por símbolos de universalidade, que o juruá, pelo desconhecimento e estranhamento cultural, ignora.

E ainda que a nós pareça que a lembrança da obragem cerâmica se esvaneceu com o tempo junto àquele grupo guarani de Niterói/Maricá (insinuadas pelas possíveis mudanças morfológicas percebidas nos artigos produzidos nas oficinas e impressas por novas implementações), essas investidas não têm a força necessária para dissipar a memória (mitológica) de importância que os cerca. Mesmo com uma gama de contatos aferidos com a realidade multimidiática e objetual do não índio, certos elementos contidos nas concepções mbyá só podem ser fornecidos e manifestados pelo ânimo pulsante do material feito de barro, já que somente este tem a precisada propriedade para os divulgar. Deste modo, as novidades construídas pelas crianças e observadas nas oficinas parecem expor, diante da sua etnicidade ainda em construção, a incorporação de aspectos tradicionais da sua histórica lide argilosa (e que estavam conhecendo em nossas reuniões) com outros informes advindos dos dados tidos de nosso contexto contemporâneo globalizado.

Imagino pelo conferido nesse projeto de atividades artísticopedagógicas por meio de oficinas cerâmicas que, organizando os informes plásticos interculturais envolvidos, esses partícipes me conduziram a pensar serem capacitados a analisar e escolher as melhores soluções visuais para as suas atuais demandas utilitário- 
estéticas dentre tudo aquilo que Ihes fora apresentado - unindo anotações de seu passado e do seu presente - e criando peças que correspondessem às noções aproximadas do que considerassem ser a aquisição de satisfação, de prazer e de contentamento na vida. Nas oficinas cerâmicas os meninos Mbyá descobriram, fantasiaram e produziram obras, transpondo para a fisicalidade do barro suas ideias a respeito do seu perfil cultural, que está em processo de construção, bem como, ainda, as suas reflexões sobre as alianças feitas com os demiurgos. Por extensão, mostraram informes comunicativos aos seus demais partidários sociais, assim impregnados de adjetivações simbólicas.

Acredito que na ambiência das oficinas cerâmicas nas tekoa bem se exemplificaram essa premissa, haja vista que os pequenos participantes guarani buscaram na convivência comigo, com os outros meninos, com os preceitos habituais de sua cultura e com os novos adquiridos com a frequentação junto à cultura "ocidentalizada", abraçar estratégias que solucionassem seus imperativos socioculturais de agora de um modo cônscio e cooperativo. Com a práxis das oficinas, vendo fotos e conversando comigo sobre tais aparelhos tradicionais de argila, essas crianças puderam melhor estruturar e perpetuar as configurações simbólicas que estão subentendidas às suas materialidades artísticas através das contações mitológicas, sem jamais desmerecê-las, apesar de todo o cabedal de saberes que geralmente angariam ante a cultura juruá. Haja vista que na produção oficineira resultante de nossas reuniões não foi abandonada a estrutura do seu modelo tradicional, contudo usando a morfologia e a pintura ancestrais, os jovens deram sentidos atualizados a ela, pois "a busca das variações leva ao conhecimento do homem enquanto ser construtor de suas próprias leis de vida" (BARÃO, 2007, p. 3).

Pondero, enfim, que também o resgate mnemônico dessa práxis em barro no meio mbyá-guarani foi o caminho delineado para favorecêlos a meditação e julgamento autônomos sobre sua importância simbólica antevista por esses objetos. E assemelha-se que, por eles sendo considerados como itens relevantes de poder de reconhecimento identitário, a chance de serem revestidos pelas possibilidades de criação, reinvenção e reinserção no mundo atual foi o frutífero saldo 
colhido em suas realidades.

Nesse sentido de ação artístico-educativa, muito se pretendeu fortalecer a compleição identitária e política desses jovens por intermédio da atividade cerâmica, pois, como signo etnocultural, tais artefatos hoje parecem estar (na Tekoa Mboy y-ty e na Tekoa Kaaguy Hovy Porã) prenhes de memórias ancestrais, de traços contemporâneos e aspectos comunais que lhes garantam a manutenção do nhanderekó/teko que os poderá guiar à sua plena felicidade.

\section{Referências bibliográficas}

BARÃO, Vanderlise Machado. O mito e o espaço nas representações artístico-culturais do Mbyá Guarani. História em reflexão, Dourados, v. 1, n. 2. p. 1-15, 2007.

CAMPOS, Maria Cristina Rezende de. A arte do corpo Mbyá-Guarani: processos de negociação, patrimonialização e circulação de memória. 2012. 157 f. Tese (Doutorado em Memória Social) - PPMS, Universidade Federal do Estado do Rio de Janeiro, Rio de Janeiro, [2012].

FRADE, Isabela Nascimento. Pedagogia do artesanato. Textos escolhidos de Cultura e Arte Populares, Rio de Janeiro, v. 3, n. 1, p. 23-36, 2006.

FRADE, Isabela Nascimento; REIS, Marluce. Elementos da visualidade Guarani contemporânea: o artesanato em seu estado de dissolução. In: ENCONTRO DE PESQUISADORES PPGA/RJ, 1., 2010, Rio de Janeiro; ENCONTRO DE ESTUDANTES DO PPGA/EBA/UFRJ, 17., 2010, Rio de Janeiro. [Des]limites da Arte: reencantamentos, impurezas e multiplicidades. Rio de Janeiro: UFRJ, Escola de Belas Artes, 2010. v. 1. p. 42-53.

GEERTZ, Clifford. A Interpretação das culturas. Rio de Janeiro: LTC Livros Técnicos e Científicos, 1989.

LADEIRA, Maria Inês. Espaço geográfico Guarani-Mbyá: significado, construção e uso. Maringá/São Paulo: Eduem/Edusp, 2008.

LAGROU, Els. Arte indígena no Brasil: agência, alteridade e relação. Belo Horizonte: Editora C/Arte, 2009.

PELEGRINI, Sandra P. A.; FUNARI, Pedro Paulo. O que é patrimônio cultural imaterial. São Paulo: Brasiliense, 2008. 
PROUS, André. A arte pré-histórica do Brasil. Belo Horizonte: C/Arte, 2007.

RAMOS, Alcida Rita. Sociedades indígenas. São Paulo: Ática, 1988.

SHADEN, Egon. Aspectos fundamentais da cultura guarani. São Paulo: EPU/ Edusp, 1974.

Recebido em: 22/09/2014* Aprovado em: 17/03/2015* Publicado em: 30/06/2015 